\title{
First-Year Students' Views on Prescribed Book for Translation Practice: A Case Study of a South African University of Technology
}

\author{
Aaron Mnguni \\ Central University of Technology \\ Welkom, South Africa \\ Email: amnguni [AT] cut.ac.za
}

\begin{abstract}
Translation as a field of study is fairly new in South Africa because before 1994, the official languages were English and Afrikaans and everybody was expected to know and use those languages. Consequently, there is not much about translation practice that is written by South African authors. Following this, translation books from outside South Africa are generally used and prescribed, thus stifling inherent experiences, since little is written by the South Africans themselves. A total number of 46 language practice students participated in this quantitative study. This study explored challenges encountered by first year language practice students, when using their prescribed book, at the Central University of Technology, Welkom Campus. Results indicated that students were not benefitting maximally from using the prescribed book, which is by any standard an excellent book. The socio-cultural experiences of the students were missing, thus prevent students' from mastering the subject content better. From the data collected, it is recommended, amongst other recommendations, that a bias towards books reflecting South African experiences be prioritized as well as also allowing students to participate in making book choices.
\end{abstract}

Keywords--- textbook, South Africa, language practice, students

\section{INTRODUCTION}

The teaching of translators and interpreters generally has always been a controversial issue (Beukes, 1994:1), especially in South Africa. Venuti (1999: 1) argues that, "Translation is treated so disadvantageously, I want to suggest, partly because it occasions revelations that question the authority of dominant cultural values and institutions. "This controversy is much more evident in South Africa. For many years in South Africa the training of translators and interpreters was not an important focus because all South Africans were expected to be able to use either Afrikaans and/ or English in all official communication. Perhaps, this state of affairs, led to a situation where translation studies, especially amongst the Africans was not seen as an important aspect and hence there was no relevant material that takes a multicultural and multilingual outlook on life that was developed for teaching and learning translation studies as a subject at the higher institutions of learning.

The Constitution of the Republic of South Africa, 1996 (Act 108 of 1996) brought fundamental changes to the table, by stating that South Africa has 11 official languages. These official languages are: Sepedi (N. Sotho), Sesotho, Setswana, Siswati, Tshivenda, Xitsonga, Afrikaans, English, isiNdebele, isiXhosa and isiZulu. Moreover, South Africa enacted the Use of Official Languages Act (2012) as well as the Language Practitioners' Act (2014) as a way of elevating the status of the official languages in South Africa, particular the historically disadvantaged languages. All these efforts by government refocused and highlighted the importance of language practitioners. It is the view of the author that the goal of producing efficient and effective language practitioners cannot be attained, unless proper teaching and learning materials, such as textbooks, are addressed.

In a number of assessments that have been done, the first-year students at CUT Welkom Campus did not perform on the expected level, and thus obtained less than $50 \%$ in the theory part of the assessment. In my discussions with the students, and in trying to establish their challenges, the issue of the textbook is cited by the students as one contributory factor. It must be stressed that there are no question marks raised about the book as it is an excellent book by any standards. The question is about general content when juxtaposed against local circumstances. Although I am of the view that there are other challenges such as the university atmosphere, university higher standard, level of high school education, and so forth that the first-year students have to grapple with, which may contribute towards a lower performance level, the issue about the textbook is still relevant and is something that needs to be researched.

On 7 May 2014, Judge Neil Tuchten in his judgement in the Limpopo textbook saga reiterated the centrality of textbooks in the realisation of pupil's rights, particular the right to basic education. (http://mg.co.za/article/2014-06-02-a-textbook- 
case). While this judgement was directed at the basic education system, it has certainly spinoffs for the higher education as well. The purpose of this paper is therefore to investigate a prescribed textbook originally targeted at readers globally, of its suitability for use by Central University of Technology, Welkom Campus, first year students on account of their socio-cultural position. On account of the small scale of this study one cannot claim statistical significance, but through this study, it is hoped that perspective will be explored regarding students' interaction with the textbook, with an aim of providing an effort that may guide further in-depth studies in this specific area that has not been researched optimally in South Africa.

\section{RESEARCH PROBLEM}

The Central University of Technology, Welkom is a fairly new institution in South Africa. Like many other institutions of the same type, they offer language practice which has become an important field of study since 1994, when 11 languages were declared official. The problem experienced is that very few books on the subject language practice have been written by South African writers in a way that addresses the South African situation. As a result, students are in a way forced to use books that are written by authors from outside South Africa. This in essence is not wrong, but students are expected to learn more about international experiences at the expense of the South African situation, even though different international authors try to carry along readers from all over the world. This phenomenon lead to a situation where students fail to relate fully to the content in the books, in relation to their experiences, and thus eventually gain a limited mastery of the content. If this challenge is not addressed, students end up regurgitating information and at times peculiar examples from other countries, while they remain largely ignorant of the local South African environment where they are likely going to work after completing their studies.

\section{LEARNING PARADIGM}

The Constructive Learning Paradigm is consequently followed in this paper as a way of correcting what could be wrong assumptions about the African cultural perspectives. According to this paradigm, learners need to grasp foundational facts and from there be able to engage with new information. This paradigm assumes that learners are not empty vessels that need to be filled with information but encounters a formal learning process with ideas and experiences previously learnt. This means that the students' background should be seriously considered when using any teaching and learning material or tool. In this particular case, the South African experiences seem to be ignored in favour of experiences from other countries, for example, using examples in the book that are often strange to the learners, and confuse students rather than assist them to acquire knowledge. Therefore, a book with relevant examples from the learners' background will allow learners an opportunity to engage meaningfully with the new information and thus come out with better results.

\section{VALUE OF THE TEXTBOOK}

Most learning and teaching centres use a standard textbook or related book or books, which assist in guiding what must be taught, when and how. Heyneman (2006:36) cites Johnsen as defining a textbook as a book whose purpose is for 'instructional use.' Mohammad and Kumari (2007:2) argue that the centrality and dominance of textbooks, particular in developing countries, has been reiterated and highlighted by various writers. In terms of the recent study done by Bolkan in 2015, most students prefer traditional texts over E-books (Bolkan, 2015). This is important in that in spite of the phenomenal technological advancements taking place, students still prefer traditional textbooks for a variety of reasons such as that textbooks are easier to read; they do not require Internet access; students find it easier to concentrate when using textbooks, and so forth. This does not mean that E-books do not have a place, but perhaps this calls for more study about how textbooks could be used jointly with other learning and teaching aids such as the Internet, or to name Central University of Technology's own computer software, called e-Thuto.

In terms of the Executive Summary of the study commissioned and funded by the Department of Arts and Culture on factors influencing the cost of books in South Africa, the South African government aims at reducing the cost of books and making books more accessible (sabookcouncil.co.za/wp-content/uploads/2019/08/cost-of-books.pdf.). In other words, irrespective of the technological development taking place all over the world in making resources available to students, books will always remain an important source even in the future. That is why the Department of Arts and Culture saw it necessary to invest into this particular study mentioned in this paragraph, with an aim of benefiting in future as a country, regarding making books available to students, and other readers.

Heyneman (2006:36) argues that people should not even imagine a modern educational system where textbooks do not play a central role. Horsley, Knight and Huntly (2010:43) in their study in Australia, reported that textbooks were recommended in every university course. Heyneman (2006:36) further argues that if textbooks are used professionally, they can be a strong pillar behind a fully educated society. Mohammad and Kumani (2007:2) support this view when they note that the centrality and dominance of textbooks, particularly in developing countries such as South Africa, has been reiterated, claimed and highlighted by various scholars such as Abbas (1993), Mohammad (1994), and many others. 


\subsection{Academic book market}

According to the study commissioned and funded by the Department of Arts and Culture (Sabookcouncil.co.za/wpcontent/uploads/2019/08/Cost-of-books-study.pdf.) in 2019, the academic book market in South Africa is underpinned by the following five arguments, resulting in reliance to a challenge of books written and published from outside South Africa:

\subsubsection{Size of the academic market}

The size of the academic market in South Africa is small. The size of the academic market does not greatly encourage writers to dedicate more time in producing academic books. What also aggravate the situation, is that each university will prefer using a particular book or books over others. If an author decides to write an academic book, because of the small size of the market, chances are that the book will be expensive unless this is offset by the international market. This is one reason why even though South Africa has a peculiar cultural way of life that needs to be used in the pedagogic sphere, there are still less if any books available in the translation field.

\subsubsection{Limited sell-through of academic books}

The sell-through rate refers to the percentage of product sold by the retailer after being shipped by its supplier. According to the study commissioned and funded by the Department of Arts and Culture (2019), the rates of the academic sell-through are as low as $50 \%$. This is not a good sign, especially when one considers that an $80 \%$ rate of sell-through will be regarded as excellent. There are many reasons contributing to this low sell-through rate such as the challenge of illegally photocopying of textbooks which is prevalent in universities these days. This trend discourages some academics from writing books in their field of specialisation. This leads the South African students to depend on books from outside the country.

Disgruntled lectures also do not actively encourage students to purchase prescribed books. Political and social statements such as 'fees must fall' had a big impact on lecturers being disinterested in taking their full role in encouraging students to purchase books and other teaching-learning resources. For example, a lecturer who pushes for students to buy prescribed books may be branded as insensitive to the plight of the poor students who are unable to purchase books as a result of socio-economic status in the South African community. This social and economic inequality is a result of the apartheid policies in South Africa that were in place until 1994. As a result of this challenge, the sell-through rate goes down, discouraging academic writers in South Africa from sharpening their skills on academic books.

\subsubsection{Under-ordering by academic booksellers}

The academic booksellers tend to order less books than the numbers required. This is because they do not want to spend money on a book and only to find that there are few students who want to buy that particular book, while the book on demand is not available. The booksellers do not seem to trust statistics given to them by universities on the number of students enrolled in a subject.

Also, booksellers sometimes miss their opportunity of having a particular book available at the correct time. Usually at the beginning of the year students tend to have funds to buy and interested to buy, and if the book is not available, the interest to buy diminishes. When the same book is available at a later date the students may have used the funds elsewhere and may not be willing to buy and as a result a low sell-through rate for the book is experienced. Under-ordering of the books scare off local writers who look at the market outside South Africa.

\subsubsection{Lack of coordination in the academic market}

There is no clear coordination between the publishers or booksellers and academic departments. Booklists are sometimes submitted late and make it difficult for booksellers to get the books available. One department may submit on time while the other later, and this increases overhead costs for the booksellers. The efficiency of ordering is affected and decreased as a result. This results also in books becoming more expensive, and students being reluctant to buy them. Some potential academic writers, particular local, are thus not willing to venture into this business.

\subsubsection{Potential concentration issues}

There are fears that the concentrated nature of the academic bookselling market may further increase the price of the academic books in future. These fears are partly responsible for many academic writers treading carefully when it comes to academic writing in South Africa. There are questions such as is there no other solution towards reducing future book costs? If so, what would be the impact of that move on the academic writers, particular local one when put in juxtaposition to international writers?

It should however, be emphasised that a textbook is an academic tool. Like any tool, it could be used to the advantage or disadvantage of teaching and learning activities. A tool in the hands of an expert will yield rewards, while the same tool in the hands of a person who does not have the appropriate level of knowledge, experience, training or skills, could have negative results. This means that an educator must not over-rely on the textbook but use the textbook together with other aids with a purpose of maximising the intellectual growth of his or her learners. 
Furthermore, Ndoleriire (2000: 269) argues that understanding cross-cultural communication is crucial in the communication amongst individuals, groups, communities as well as nations. Taking from what he says, this is also an important issue that must be explored by students, particular in Africa. If this is not taken into consideration, a 'noise factor', which is miscommunication, will result. Ndoleriire (2000: 275) goes on to discuss factors such as non-verbal factors, paralinguistic factors as well as discourse conventions factors which are integral part of communication, and perhaps language practice training. In other words, language practitioners in South Africa, and indeed in Africa, cannot function properly without the following dimensions. Examples relate the identified aspects are as follows:

\subsection{Communication cross-cultural factors}

The following factors are important to understand, in order to ensure that good language practitioners are produced through the literature that is used in the universities of technology:

\subsubsection{Non-verbal factors}

Non-verbal factors are very important to understand particular when writing a book that seeks to teach language practitioners. A practical example in this one for example, may be the physical distance between the speaker and the interpreter. In Africa, an interpreter may be doing their task inaptly if they happen to stand too close to the speaker, if the speaker is holding a high position in the community such as being a king, or an herbalist. No matter how good an interpreter may be, adhering to this this dimension could mean failure or success of their task as interpreters. To show the importance of this aspect, Ndoleriire (2000:276) mentions that Dr Kabizwe, knelt before Mandela while interpreting. This could be regarded as weird or strange by translators who are not familiar with the South African experience. This is just one indication that there are many other aspects translators in South Africa still need to be exposed to, which unfortunately most of the literature on translation is silent about, and thus fail to aptly assist translators who will in the South African or even African context.

\subsubsection{Paralinguistic factors}

The pitch of the voice when translating for example, can have a specific meaning. Biko (2004: 45) argues that Africans are 'man-centred' societies. This is in stark contrast to the western perspective of being individualistic. Biko argues further that, in traditional African societies, there are no two friends. Conversation groups are formulated along age and division of labour, and so forth and thus there are usually many people one could call friends at any particular time. High pitches would mean excitement within the peer group, for example, and so forth. When interpreting for example, knowledge of this aspect is important. For the western people, a high pitch may sound cold, and perhaps also as a sign of frustration or fear. This is thus important for translators and particular the interpreters to understand.

\subsubsection{Discourse conventions factors}

Greetings and forms of address differ significantly amongst different people. In Africa, for example, greeting tend to be long, while other nations, particular the west, may regard this as unnecessary and time wasting. Another example, in English for example, when a person asks after your health, you would thank them first and go on tell them about your state of health. Amongst many African language speakers, you will only thank the person once they have told you that they are well. In other words, you do not thank them for asking after your health, but you thank the fact that they are well.

In the light of these arguments, there is much that language practitioners in South Africa need to be exposed to in order to be recognised as competent language practitioners. It is these experiences that could form part of the curriculum or content of textbooks that are used to train language practitioners that will ultimately work in the South African or African context.

\section{RESEARCH DESIGN}

A quantitative research design was followed in this study. Fox and Bayat (2012: 77) define quantitative research design as involving investigations where relative data is analysed in terms of figures that may be quantified or summarised. In order to address the problem identified above, a survey research was selected because the population to be investigated was not small. A questionnaire technique was found to be appropriate especially because the respondents are students and the population or universum of a total of 46 students in the course in Welkom Campus was used, and thus no sample selection was necessary.

\subsection{Purpose of research}

According to Fox and Bayat (2012: 30) there are three aims of research, viz. exploration, description and explanation.

\subsection{1. exploration}

Exploration carefully looks at a topic or the basic awareness of the topic. This approach is useful when a new subject is explored or the subject itself is relatively new. Here, the researcher is interested in acquiring understanding about a new phenomenon. The important question in this approach is, how. This assist in breaking new ground, and as a result present 
fresh and new insights into the topic being investigated. Babbie (2007: 88) however, argues that exploratory studies have a weakness of seldom providing adequate answers to research questions.

\subsection{2. description}

The aim of this approach is to describe a situation and events under investigation. It is the duty of the researchers here to make a careful observation on the phenomenon under investigation, and thereafter describe what they observed. This observation is different from spontaneous observation which may not be scientifically accurate. This approach usually answers the question, what?

\subsection{3. explanation}

The explanation approach explains things in the research exercise. The important question in this approach is why. There is usually an indication as to the causality between events or variables.

In this article, the exploratory aim is pursued in order to break new ground in the field of academic literature that may maximally benefit the students at the university of technology. While it is noted that there is a challenge of not cracking into adequate answers posed by the research, open-ended nature of the questionnaire seeks to complement this weakness. The explanatory aspect of the research aims is also touched in this research in that the why questions regarding book choices, and so forth, are answered.

\subsection{Questionnaire}

A survey research questionnaire was designed to investigate various aspects related to the use of a prescribed textbook by the Language Practice first year students, CUT, Welkom Campus. Fox and Bayat (2012: 87) defines survey research, "as collecting data by putting a set of pre-formulated questions, in a pre-determined sequence in a structured questionnaire." However, this questionnaire was open-ended, to allow further inputs from the students on the issues indicated in the questionnaire. The use of an open-ended questionnaire has been adopted in this study mindful of the fact that surveys have many advantaged, as well as disadvantages. Amongst other advantages, the survey research made it possible to conduct a research to a large-scale respondent in a faster, easy and relatively cost-effective manner.

A total number of 46 students present on the day were involved as respondents in this study. The majority of the respondents (44. 2) passed English as an additional language on level 5. Most respondents are between the ages 18 and 29 and had a mean age of 21.2 years. The majority of the respondents are doing the course for the first time (91, 3\%), therefore their first encounter with the textbook. This is important to clarify as there is about $8.7 \%$ students who are not seeing the textbook for the first time. A response rate of $100 \%$ indicate that the exercise was fruitful, as low response rate often invalidates results because of the difference between respondents who participates and those who do not participate. Participants were responding to questions with assurance that data gleaned will be treated anonymously.

\subsection{Ethical considerations}

In social research projects, ethical concerns are crucial. Babbie (2007:80) argues that what is considered ethical or unethical depend on what a community of people agree is wright and wrong. For research, participants should not be coerced to participate against their will. In this research the students were informed, and it was clearly indicated in the questionnaire that their participation is voluntary, and they are free to stop participating at any stage of the research without giving any explanation if they feel like doing so. This was to ensure that they participate only if they feel like doing so.

The participants were also informed that their names will not be used and could not be linked in any way to them with regards to the research. In other words, whatever information they give, it will be treated with strict confidentiality. A student is free to express their views without fear of repercussions or perceived discrimination against them at any stage in their learning process. The researcher wanted honest opinions of the learners and thus created an atmosphere where the learners were not threatened in any way. Thus, the participants' responses are treated respectfully and also remained anonymous (Theron, 2012: 93).

The Institution involved, Central University of Technology has an ethical code in place which had to be followed throughout the research process. This ethical code is meant to ensure that participants are not injured in any way, physically, emotionally or spiritually. The researcher also ensured that reporting of the results is done fully, accurately and fairly to both the community of researchers as well as participants.

\section{RESULTS AND DISCUSSION}

The questionnaires administered in this research exercise have rendered the following data distribution, which is analysed and discussed in this section in terms of the questions asked, and responses plotted in different tables, for each question: 
Table 1: Do you find the textbook easy to read and understand?

\begin{tabular}{|l|l|l|l|}
\hline & Frequency & Percent & Valid Percent \\
\hline Yes & 2 & 4.3 & 4.3 \\
\hline No & 44 & 95.7 & 95.7 \\
\hline Total & 46 & 100.0 & 100.0 \\
\hline
\end{tabular}

Considering that students have to spend a large portion of their study time doing independent studies outside the lecture hall, it is important that they are able to read and understand a prescribed book easily, especially if such a book could be regarded as a main source. The majority of the respondents (95.7\%) according to Table 1 above in this study, do not find the book either easy to read or to understand. While Grant (S.a.: 118) argues that there is nothing that could be called a perfect textbook, he strongly feels that nevertheless, a textbook should be designed in such a way that it takes into cognisance the learning styles and needs of each and every student. In the case where more than $95 \%$ respondents claim to find the textbook difficult to read or understand, then clearly something needs to be done to correct this unfortunate situation. In his three pillars for the evaluation of textbooks, Grant (S.a.:118) puts the needs, interests and abilities of the students prominently.

Table 2: Is the language used in the book clear and simple to you?

\begin{tabular}{|l|l|l|l|}
\hline & Frequency & Percent & Valid Percent \\
\hline Yes & 13 & 28.3 & 28.3 \\
\hline No & 33 & 71.7 & 71.7 \\
\hline Total & 46 & 100.0 & 100.0 \\
\hline
\end{tabular}

More than $71 \%$ of the respondents according to Table 2 above, regard the language used in the book as unclear, and complex. This is an important aspect, considering that more than $44 \%$ of the respondents passed English as an Additional Language on level 5 in Grade 12 or equivalent. In South Africa the question of language of teaching and learning is a topical issue. There are debates as to how and why the language of teaching and learning must be the mother-tongue of the students. While the mother-tongue is a target, South Africa is still a way before realising this fully in all levels of the education system. Bruner (2001) argues that when choosing a textbook, it should always be remembered that the real audience is the student. Such a book must therefore focus on the student, meaning that it should not be too easy or too difficult for the student. The lecturer, the authorities, or the facilitator are not the real determinant of a good textbook in terms of clarity and simplicity, although they may still offer some advice in this particular aspect.

Table 3: Is the terminology used appropriate for your level of understanding?

\begin{tabular}{|l|l|l|l|}
\hline & Frequency & Percent & Valid Percent \\
\hline Yes & 2 & 4.3 & 4.3 \\
\hline No & 44 & 95.7 & 95.7 \\
\hline Total & 46 & 100.0 & 100.0 \\
\hline
\end{tabular}

In terms of Table 3 above, most of the respondents are of the view that the terminology used in the book is inappropriate for their level of understanding and thus in short, beyond the level of the respondents' understanding. One respondent in the open-ended part of the questionnaire added that the terminology used in the textbook necessitates frequent use of a dictionary and to rely on someone to explain some terms before they could understand. This, no doubt, demotivates the students from reading on their own, and thus the results on the theory part of the translation module are not at a maximum potential level of the students.

Table 4: Do you consider the information given in the textbook too little or too much?

\begin{tabular}{|l|l|l|l|}
\hline & & & \\
& Frequency & Percent & Valid Percent \\
\hline Yes & 7 & 15.2 & 15.2 \\
\hline No & 39 & 84.8 & 84.8 \\
\hline Total & 46 & 100.0 & 100.0 \\
\hline
\end{tabular}

More than $84 \%$ of the respondents believe that the book is giving too much information. Too much information above the level of the respondents may be a challenge. One respondent said that this book is one of the most difficult books in their 
courses, and for them also, it is too advanced. About 11 students (who added comments on the appropriate section of the question) pointed at Section B of the Book which comprises mostly scholarly papers read that are relevant to the topic under discussion, as an example of too much information given to them as users. The feeling is that a summary of the paper will suffice in a form of content of that specific topic under discussion rather than having the whole paper included.

Table 5: Are examples used in the textbook relevant to you and easy to follow?

\begin{tabular}{|l|l|l|l|}
\hline & Frequency & Percent & Valid Percent \\
\hline Yes & 6 & 13.0 & 13.3 \\
\hline No & 39 & 84.8 & 86.7 \\
\hline Total & 45 & 97.8 & 100.0 \\
\hline Missing System & 1 & 2.2 & \\
\hline Total & 46 & 100.0 & \\
\hline
\end{tabular}

About $86,7 \%$ of the respondents are of the opinion that examples used in the Book are not relevant to them and thus not easy to follow. One respondent said the examples are based on Western culture and is therefore foreign to them. If examples are taken from what students experience daily or from their culture, it helps students to follow the content easier. Example,

(a) UmkaThemba uyagula. (Themba's wife is ill).

(b) Umka-Mary uyagula. (Mary's wife is ill).

Sentence (a) is acceptable, while sentence (b) may create problems for some (if we accept that Mary is female), but normal and acceptable amongst the Ndebele speakers in South Africa.

Knowing such peculiarities will equip students to relate better to the South African context. A book aimed at students from all over the world will unfortunately fail to address such aspects adequately as people and consequently their culture all over the world are diverse and different. While South Africa may be regarded as a minor player in the international space when it comes to cultural dominance, but examples such as the ones mentioned in (a) and (b) are just too numerous and loud to ignore in the South African context. In addition, Seguin (1989:10) identifies the socio-cultural context and the language of instruction as important consideration in delivering quality textbooks that addresses the specific needs of the learners in the educational encounter.

Table 6: Are you able to easily read and understand the textbook on your own?

\begin{tabular}{|l|l|l|l|}
\hline & Frequency & Percent & Valid Percent \\
\hline Yes & 6 & 13.0 & 13.3 \\
\hline No & 39 & 84.8 & 86.7 \\
\hline Total & 45 & 97.8 & 100.0 \\
\hline Missing System & 1 & 2.2 & \\
\hline Total & 46 & 100.0 & \\
\hline
\end{tabular}

The majority of the respondents believe that the book has too much information, and therefore creates confusion. It makes it difficult for students to make pre-studies, which is an important activity for students before attending a specific lecture. The lecturer is often confronted by students who want to be given notes as they are unable to read and understand the book on their own. This, however, does not mean that the lecturer will not be doing his or her work in class but merely indicate that students need to do much reading work on their own.

Table 7: Is the textbook in line with your culture and your general way of understanding things?

\begin{tabular}{|l|l|l|l|}
\hline & Frequency & Percent & Valid Percent \\
\hline Yes & 18 & 39.1 & 40.0 \\
\hline No & 27 & 58.7 & 60.0 \\
\hline Total & 45 & 97.8 & 100.0 \\
\hline Missing System & 1 & 2.2 & \\
\hline Total & 46 & 100.0 & \\
\hline
\end{tabular}


This is a crucial aspect, as the book itself claims to deliver information in a way that addresses cultural diversity. However, in terms of Table 7, 60\% of the respondents do not agree that cultural diversity has been achieved. This is an important and a sensitive issue in South Africa, where before 1994, the culture and the way of understanding of the majority of the citizens of the country was violated, and the state pretended as if the culture and philosophy of life of the majority in general did not exist. It is no wonder then that majority of the students would prefer this particular aspect to be addressed in their textbooks. Venuti (1999: 6) champions an ethical stance that urges translations to be written, read and evaluated with great respect for linguistic and cultural differences. In other words, training language practitioners with an emphasis on linguistic differences only, and merely scratching the surface when it comes to cultural differences is grossly unfair. Venuti (1999:23) goes on to say that emphasis on linguistics in translation is actually a conservative approach that goes on to unduly limit the unquestionable role of translation, in cultural innovation and social change. Similarly, in the preface to his publication entitled, The Elaboration of School Textbooks, Seguin (1989) argues that a crucial challenge facing educational authorities is to make available textbooks that are adapted to the social and cultural context of their countries and also ensure that such textbooks meet the needs of their respective educational system.

Table 8: Would you recommend that we continue using the same textbook?

\begin{tabular}{|l|l|l|l|}
\hline & Frequency & Percent & Valid Percent \\
\hline Yes & 5 & 10.9 & 11.4 \\
\hline No & 39 & 84.8 & 88.6 \\
\hline Total & 44 & 95.7 & 100.0 \\
\hline Missing System & 2 & 4.3 & \\
\hline Total & 46 & 100.0 & \\
\hline
\end{tabular}

More than $88 \%$ of the respondents recommend that using the textbook be discontinued. This is indeed a challenge, considering that there are not enough and suitable resources available in South Africa that address adequately concerns raised by the students. This is perhaps a clarion call to authors and publishers in South Africa to seriously look at meeting the students' need in this particular aspect.

\section{CONCLUSION}

From these research results it appears that having students contributing in the selection of a prescribed or a range of alternative textbooks could be useful. Also, while the contribution by authors from all over the world in the available sources is acknowledged, perhaps it is time that South Africans publish more work in the field of translation, where the experiences of the South Africans will be emphasised. This therefore, calls for more and in-depth research on this topic. Many examples in our communities and our diverse culture could contribute to the enrichment and preparation of our student language practitioners to excellent service in the South African context, and beyond.

\section{REFERENCES}

- $\quad$ Babbie, E. 2007. The Practice of Social Research. Thomson Wadsworth: USA.

- Beukes, A.M. 1994. Social transformation and translator and interpreter training: In Kruger, A (ed.): New perspectives on teaching translators and interpreters in South Africa. University of South Africa: Pretoria. 1-9.

- $\quad$ Biko, S. 2004. I write what I like. Picardor: Johannesburg.

- Bolkan, J. 2015. Most Students Prefer traditional text over E-books [Online]. Available from: http://campustechnology.com/articles/2015/09/01/Survey-Most-Students-prefer-tra. (Accessed on 25 April 2016).

- Brookes eJournal of Learning and Teaching. 2006. Textbooks in Teaching and Learning, Vol 2, issue One 2006 [Online]. Available from: http//bejlt.brookes.ac.uk/paper/textbooks_in_teaching and _learning-2/. (Accessed on 02 September 2015).

- Bruner, M. 2001. Efficient and Effective Use of the Textbook [Online]. Available from: www.phschool.com/eteach/social_studies/2001_05/essay_html. (Accessed on 29 September 2015).

- $\quad$ Fox, W \& Bayat, M.S. 2012. A guide to managing research. Juta: Cape Town.

- Grant, N. (S.a.) Making the most of your textbook. Longman: London.

- Heyneman, SP. 2006. The role of Textbooks in a Modern System of Education: Towards High Quality Education for All. Vanderbilt University.

- Horsley, M, Knight, B \& Huntly, H. 2010. The role of textbooks and other teaching learning resources in higher education in Australia: change and continuity in supporting learning. IARTEM e-Journal, Vol. 3 No. $2.43-61$.

- $\quad$ http://mg.co.za/article/2014-06-02-a-textbook-case (Accessed on 19 April 2016).

- Mohammad RF \& Kumari, R. 2007. Effective Use of Textbooks: A Neglected Aspect of Education in Pakistan. Journal of Education for International Development. Pp. 1-11. 
- Ndoleriire, O.K. 2000. Cross- cultural communication in Africa: In Webb, V. \& Kembo-Sure (eds)., African Voices. Oxford University Press Southern Africa: Cape Town. 268-285.

- Sabookcouncil.co.za/wp-content/uploads/2019/08/Cost-of-books-study.pdf. (accessed on 05 November 2019).

- Seguin, R. 1989. The Elaboration of School Textbooks: Methodological Guide. UNESCO.

- The Constitution of the Republic of South Africa, 1996 (Act 108 of 1996). Pretoria: Government Printers.

- Theron, LC. 2012. The ethics of Article Publications. In: First steps in Journal Article writing. Maree, JG. (Ed). Juta: Cape Town.

- Venuti, L. 1999. The Scandals of Translation: Towards an ethics of difference. Routledge: New York. www.salanguages.com/legislation.htm (Accessed on 24 May 2016). 